\title{
A CRITICAL EVALUATION OF HARD CHROME COVERED ROLLING MILL ROLLS*
}

\author{
Antonio Fabiano de Oliveira ${ }^{1}$ \\ Guilherme Frederico Bernardo Lenz e Silva ${ }^{2}$ \\ Eduardo Nunes ${ }^{3}$ \\ Ronald Lesley Plaut ${ }^{4}$ \\ Ricardo Lívio Ferreira Oliveira ${ }^{5}$ \\ Karl Kristian Bagger 6 \\ Célio Souza do Rosário ${ }^{7}$
}

\begin{abstract}
The aim of the present research work is to study the influence of hard chrome covered skin pass cold rolling rolls using 2D/3D surface topography, i.e. roughness characterization. The common stochastic structure Shot Blast Texturing (SBT) does not meet all requirements related to the production line regards to the finished product. The Hard Chrome layer, applied on these SBT rolls, can improve the sheet surface quality and is of fundamental interest mainly for those steel mills that do not have another alternative to new surface structures such as those that may be provided by the EDT, LT, EBT, etc. methods. The function of the generated surfaces, obtained by these different methods is going to influence the tribological properties during the subsequent forming processes. On the other hand, they can increase the product final cost or require large investments to obtain such surfaces. The results here presented are in accordance with other recently published research work, showing that there is a relationship between these parameters, and that further detailed studies are needed.
\end{abstract}

Keywords: 3D roughness; Surface topography; Skin pass; Operational window.

1 PhD student USP; manager CRC do Sul, Mauá, SP, Brasil; antonio.fabiano@crcdosul.com.br.

PhD and Prof. Dr., USP, SP, Brasil; guilhermelenz@usp.br.

PhD USP; Metallurgical Engineer GM Brasil, SP, Brasil; eduardo.nunes@gm.com.

PhD and Prof. Dr., USP, SP, Brasil; rlplaut@usp.br.

Director CRC do Sul, Mauá, SP, Brasil; ricardo.livio@crcdosul.com.br.

Technical manager Usiminas-Cubatão, SP, Brasil; karl.bagger@usiminas.com.

TCM/Temper Mill manager Usiminas-Cubatão, SP, Brasil; celio.rosario@usiminas.com. 


\section{INTRODUCTION}

Freshly groundwork rolls for temper rolling mills generally undergo two additional preparation processes before each mill campaign:

1) A surface texturing process, in order to apply the required roughness. The most widely used technique is Electrical Discharge Texturing (EDT). However, for some companies the texturing used is via Shot Blasting (SB), mainly due to the associated lower cost.

2) Hard chrome plating process, in order to enhance the wear resistance of the textured roll surface, is used to prevent from frequent work roll changes due to premature roughness loss.

This paper discusses the fundamentals of the Hard Chrome Plating (HCP) technology as well as several developments on an industrial application scale of HCP for Temper Mill work rolls [1].

Studies of the effect of temper mill variables such as, Work Roll Uncoated (WRU) and Work Roll Coated $(\mathrm{WRC})$, i.e. $(\mathrm{WRC}=\mathrm{WRU}+\mathrm{HCP})$, surface topography (characterized by 2D and 3D) roughness parameters has the objective of improving the quality of strip and increasing the productivity of mill.

In these trials, the HPC variants performed are related to roughness retention, in other words, an improvement of the value-in-use of a work roll that implies a superior wear resistance of WRC in relation to the WRU.

\section{LITERATURE REVIEW}

\subsection{Principle of Hard Chrome Plating (HCP)}

Hard chrome plating is an electroplating process in which chromium is deposited in a chromic acid solution, see Figure 1. The chemical reactions in a chrome plating system are not quite simple. Besides oxygen and hydrogen evolution, a positively charged chromium complex is reduced to chromium metal at the cathode surface; some $\mathrm{Cr}(\mathrm{VI})$ is also partially reduced to $\mathrm{Cr}$ (III) at the cathode surface [2]. The Hexavalent Chromium is a heavy metal and therefore proper care about technical and environmental aspects should be taken during handling and application of the chrome layer [2].

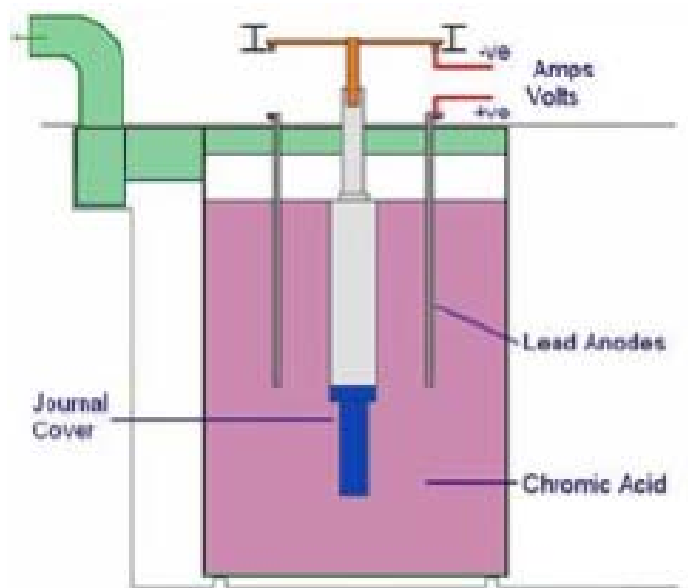

Figure 1: Schematic diagram of the HCP process [2] 


\subsection{Parameters of HCP on work rolls}

It is essential that the micro-cracked and porous coatings over work rolls has a minimum thickness between $80-120 \mu \mathrm{m}$ in order to confer adequate corrosion resistance. Micro-cracked chromium has a Vickers hardness of $800-1000 \mathrm{~kg} / \mathrm{mm}^{2}$, while crack-free chromium has a Vickers hardness between $425-700 \mathrm{~kg} / \mathrm{mm}^{2}$. The formation of micro-porous chromium is achieved by a specialized plating method involving the use of inert suspended particles. Porous chrome plating is developed by etching the electrodeposited chromium. These are designed to retain lubricant and consequently lower coefficient of friction during the rolling process [2].

Chrome plating has been used for wear control with focus on tribological (low friction) characteristics, and to produce via electroplating a thin layer of metallic chrome onto the work roll barrel [2]. The chrome lowers the coefficient of friction in the roll bite, and micro cracks in the chrome layer can improve the roll bite lubrication and, hence, reduce roll force, consequently lowering power consumption and allowing larger reductions. In addition, the protective layer provided by the chrome plating and the improved lubrication reduces the creation of iron fines, therefore improving cleanliness in the strip cold mill [3].

\subsection{Characterization of WCR Surface}

The HCP has been used in operation to obtain a specific surface finish in steel sheet stampings with the purpose to improve the material's stampability.

This characteristic allows the plating to be utilized for a long time to withstand both wear and creating oil pockets. Figure 2 below, shows a smooth surface of hard chrome plating which limits oil penetrating ability into the plate to help lubricate the surface. Comparing the surface of the substrate to the surface of the plating, it shows the plating tends to mimic the surface of the substrate.
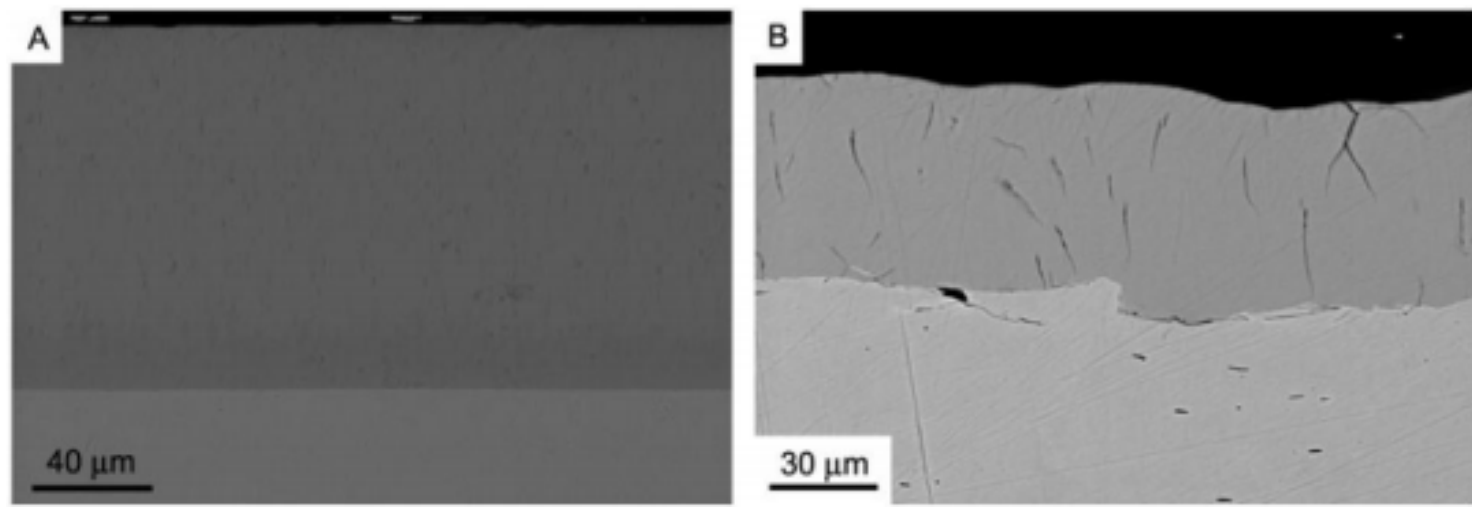

Figure 2: SEM micrographs HCP coating cross-section: $(A)$ double plating on polished substrate and (B) flash plating on grit-blasted surface [4]

As shown by Giovanni et al. [4], the addition of microcracks into the surface will add both benefits and weaknesses related to oil retention and other characteristics of the plating. Microcracks can be formed during the deposition process. With the microcracks, the coating will be much harder, increasing the wear resistance however, corrosion resistance and fatigue life will be reduced. The microcracks will allow oil to penetrate the surface increasing the lubrication to extend life of the coating and of the work roll. However, without these microcracks, coating life will be 
limited because it will be a softer coating with increased wear rates and less oil can be retained to aid lubrication and ultimately extending roll life [5].

\subsection{D surface analysis}

The roughness characterization of technical surfaces based on 2D description is not quite satisfactory for many industrial applications. Therefore, with rapid development with new measuring methods based on powerful computer generation techniques, the introduction of 3D surface parameters into research and industry is taking place [6].
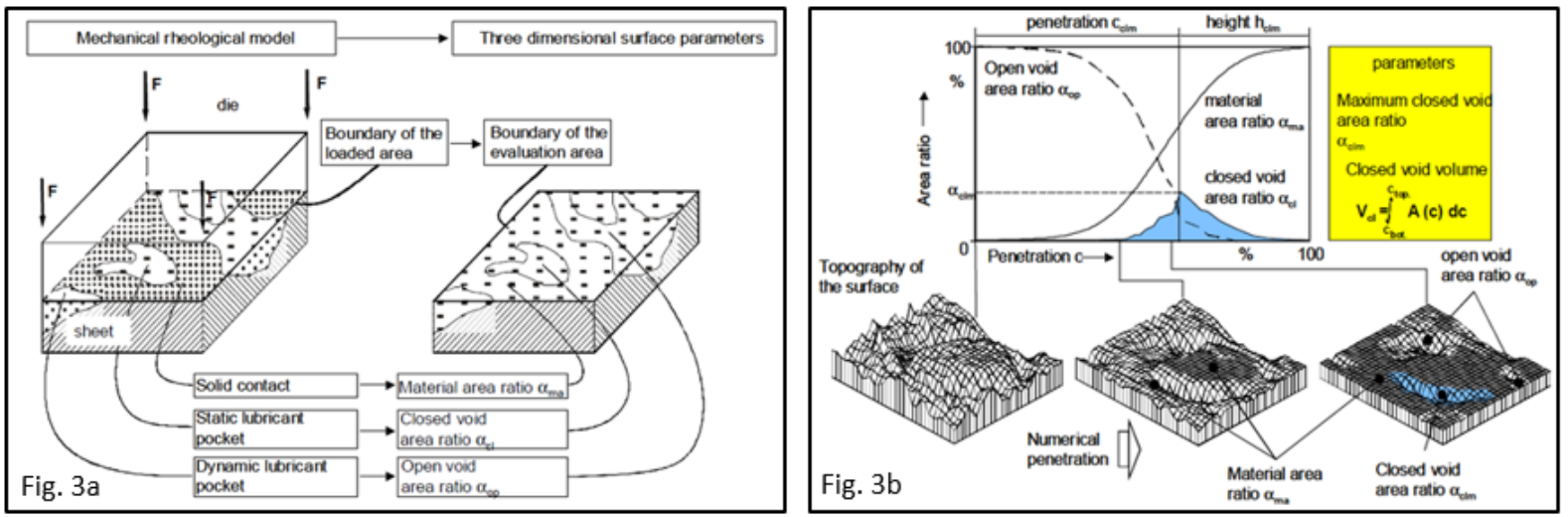

Fig. 3a - Definition of 3D-surface parameters [6] and Fig. 3b - Material ratio, as well as the open and closed void ratio using the example of the lubricant crater of a Lasertex surface and definition of vertical parameters according to [7].

As shown in Figure $3 a / 3 b$, the relative amount of solid contact corresponds to the material area ratio. The 3D surface parameters for the static and dynamic lubricant pockets are the closed void area ratio and the open void area ratio [6]. The material area ratio has already been introduced by Stout [7] as a useful tool for comparative analysis of surfaces, based upon a three-dimensional measurement of the surface.

\subsection{Parameters for lubrication performance evaluation of a 3D plateau structured surface}

These are 3D parameters expanded from the roughness (2D) parameters for lubrication performance evaluation of a plateau-structured surface (Rk, Rpk, Rvk, Mr1, Mr2). This is shown in Figures $4 a$ and $4 b$ :
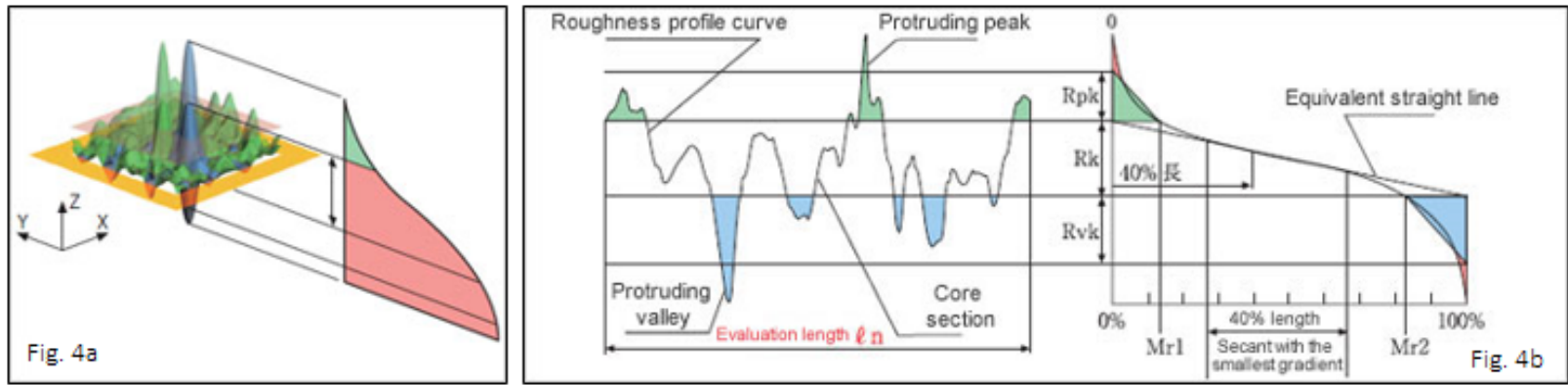

Fig.4a: Height characterization using the liner material ratio curve [3] and Fig.4b Height parameters (peaks/valleys) [3]. 
Parameters related to the volume of the void portion and the material portion are defined as shown in the Figure 5. Thus, $10 \%$ and $80 \%$ are default values of the heights for the boundaries among the valley section, core section, and peak section. These parameters are defined below:

- Vvv: The void volume of the valley section, as calculated from the material ratio curve;

- Vvc: The void volume of the core section, as calculated from the material ratio curve;

- Vmp: The material volume of the peak section, as calculated from the material ratio curve;

- Vmc: The material volume of the core section, as calculated from the material ratio curve.

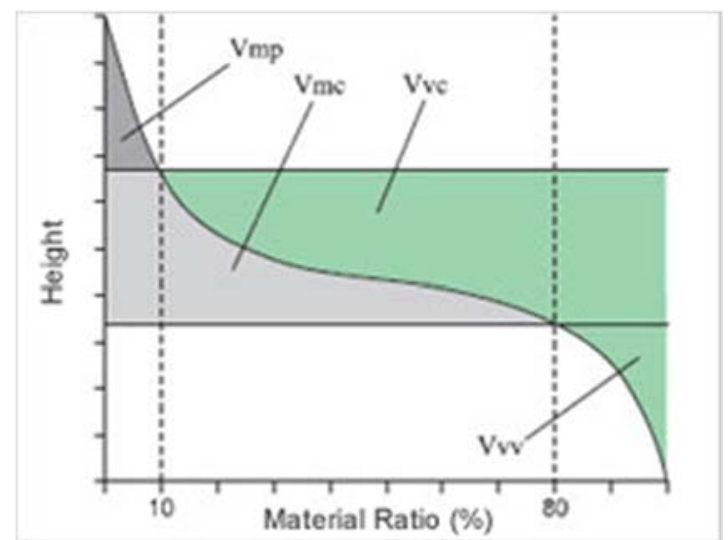

Figure 5 - Void Volume and Material Volume [3]

\subsection{Temper Mill Reduction}

After the roll texturing process has been finished, the roll-surface structure has to be transferred to the sheet metal. This process is obtained through the Temper Mill (TM). Previous studies have been performed on the transfer characteristics of the different work roll surfaces onto the sheet metal in terms of TM reductions [8].

Practical data obtained from steel mills have shown a threefold increase in roll life (measured via decrease in Ra values) of the texturized Cr-plated rolls [9]. Furthermore, Simão and Aspinwaal, have shown that roll performance is a function of roll roughness, see Figure 6 [10]. It may be observed that as the roll roughness decreases the gain in roll life, associated to the chromium plated versus plain temper, also increases. This difference in roll life related to roll roughness has been associated with the breaking of the roll roughness peaks [10]. The authors could not find any information related to the simultaneous evolution of Ra values for both, i.e., the roll and the sheet metal. This research will try to analyze this aspect.

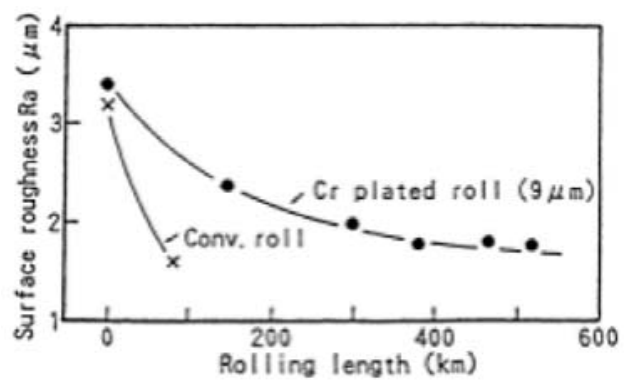

Figure 6: Comparative performance of chromium plated and temper mill rolls [10]. 


\section{MATERIAL AND METHODS}

\subsection{Replica Authentication}

The analysis of roughness over work rolls and on the sheet metal was made possible with the support of surface replicas. The resin Zhermack colorbite D [11] was used to produce the replicas. The capability to replicate the topography was evaluated initially in this work.

A comparative method replica resin versus standard block to permit to evaluate the surface topography of temper work rolls, see Table I. The Sa roughness average in both situations, for the original standards of $6,0 \square \mathrm{m}$ and $0,86 \square \mathrm{m}$, are compared in Table I.

Table I - Results of measured parameters between on replica and on a standard

\begin{tabular}{|c|c|c|c|c|c|c|c|c|c|c|c|}
\hline \multicolumn{3}{|c|}{ Measured on standard } & \multicolumn{3}{|c|}{ Measured with replica } & \multicolumn{3}{|c|}{ Measured on standard } & \multicolumn{3}{|c|}{ Measured with replica } \\
\hline \multicolumn{3}{|c|}{ Height Parameters } & \multicolumn{3}{|c|}{ Height Parameters } & \multicolumn{3}{|c|}{ Height Parameters } & \multicolumn{3}{|c|}{ Height Parameters } \\
\hline Sa & 0.5846 & um & $S q$ & 0.8056 & um & Sq & 6.2833 & um & Sa & 6.596 & um \\
\hline Sak & 0.1327 & & Ssk & 0.1300 & & Sak & 0.1021 & & Ssk & 0.07254 & \\
\hline Shy & 1.558 & & Shu & 1.560 & & She & 1.782 & & Shy & 1.813 & \\
\hline So & 1.571 & $\mu \mathrm{m}$ & So & 1.528 & $\mu \mathrm{m}$ & So & 13.29 & um & So & 12.66 & $\mu \mathrm{m}$ \\
\hline Sv & 2.437 & $\mu \mathrm{m}$ & Sv & 1.450 & $\mu \mathrm{m}$ & Sv & 11.67 & $\mu \mathrm{m}$ & Sv & 12.49 & $\mu \mathrm{m}$ \\
\hline Sz & 3.009 & um & sz & 2.979 & um & sa & 24.8 & um & Sz & 25.15 & um \\
\hline So & 0.7900 & um & so & 0.7906 & um & So & 6.004 & um & So & 5.961 & um \\
\hline \multicolumn{3}{|c|}{ Functional Parameters } & \multicolumn{3}{|c|}{ Functional Parameters } & \multicolumn{3}{|c|}{ Functional Parameters } & \multicolumn{3}{|c|}{ Functional Parameters } \\
\hline $\sin r$ & 32.47 & $\mathbf{s}$ & $\sin r$ & 33.75 & $\mathbf{s}$ & $\sin x$ & 0.3907 & $\mathbf{4}$ & $\operatorname{sen} r$ & 2.057 & $\mathbf{5}$ \\
\hline $\sin x$ & 2.176 & $\mu \mathrm{m}$ & $\sin x$ & 1.004 & $\mu \mathrm{m}$ & $\sin x$ & 9.254 & $\mu \mathrm{m}$ & $\sin x$ & 9.765 & $\mu m$ \\
\hline $\operatorname{sip}$ & 1.142 & $\mu \mathrm{m}$ & $\operatorname{Sxp}$ & 1.148 & $\mu \mathrm{m}$ & Sxp & 10.45 & $y m$ & Sxp & 10.53 & $\mu \mathrm{m}$ \\
\hline \multicolumn{3}{|c|}{ Functional Darameters (Volu... } & \multicolumn{3}{|c|}{ Functional Parameters (Volu... } & \multicolumn{3}{|c|}{ Functional Parameters (Volu... } & \multicolumn{3}{|c|}{ Functional Darameters (Volu.. } \\
\hline $\mathrm{Vm}$ & 0.00706 & $\mu m^{2} / \mu m^{2}$ & $\mathrm{Vm}$ & 0.006926 & $\mu m^{\prime} / \nu m^{2}$ & $\mathrm{Vm}$ & 0.1266 & $\mathrm{um} / / \mathrm{m}^{2}$ & Vm & 0.1251 & $\mu m^{2} / / m^{2}$ \\
\hline vv & 1.267 & $\mu m^{2} / \mu m^{2}$ & w & 1.269 & $\mu m^{3} / \nu m^{2}$ & w & 10.01 & $\mathrm{um} / / \mathrm{m}^{2}$ & w & 9.590 & $\mu m^{2} / m^{2}$ \\
\hline Vmo & 0.00706 & umV/um* & Vmo & 0.006926 & $4 \mathrm{~m}^{2} / \mathrm{um} \mathrm{m}^{2}$ & Vmp & 0.1266 & $\mathrm{um}^{2} / \mathrm{m}^{2}$ & Vino & Q.125: & $\mu m^{2} / / m^{2}$ \\
\hline Vke & 1.245 & $\mu m^{*} / \nu m^{2}$ & We & 1.247 & $\mu m^{2} / \nu m^{2}$ & We & 9.618 & $\mathrm{um}^{2} / \mathrm{m}^{2}$ & We & 9.422 & $\mu m^{2} / / m^{2}$ \\
\hline $\operatorname{Vmx}$ & 1.017 & $\mu m^{2} / \mu m^{2}$ & $V \operatorname{ma}$ & 1.020 & $\mu m^{2} / / \mu m^{2}$ & $\operatorname{Vin} x$ & 7.506 & um $1 / \mu m^{2}$ & Vme & 7.375 & $\mu m^{2} / / m^{2}$ \\
\hline $\mathrm{Vw}$ & 0.02155 & $\mu m^{2} / \mu m^{2}$ & Ww & 0.02173 & $\mu m^{2} / / \mu m^{2}$ & Ww & 0.3924 & $\mathrm{um}^{2} / / \mathrm{m}^{2}$ & $W_{w}$ & 0.4672 & $\mu m^{2} / / m^{2}$ \\
\hline \multicolumn{3}{|c|}{ Feature Parameters } & \multicolumn{3}{|c|}{ Feature Parameters } & \multicolumn{3}{|c|}{ Feature Parameters } & \multicolumn{3}{|c|}{ Feature Darameters } \\
\hline$S p c$ & 0.4059 & $1 / 1 / \mathrm{m}$ & $S \rho x$ & 0.3562 & 1/vm & $S \propto x$ & 3.595 & $1 / 1 / m$ & Sox & 9.450 & $1 / 4 \mathrm{~m}$ \\
\hline $510 z$ & 1.185 & $\mu \mathrm{m}$ & $510 z$ & 2.264 & um & $510 z$ & $\cdots \cdots$ & $\mu m$ & $5: 0 z$ & 12.25 & $\mu m$ \\
\hline$S S_{p}$ & 0.7447 & $u m$ & S50 & 1.117 & um & 550 & $\cdots \cdots$ & um & SSP & 4.778 & um \\
\hline $55 v$ & 0.4406 & um & S5V & 1.146 & un & S5. & $\cdots \cdots$ & $u m$ & SSV & 7.496 & um \\
\hline Sda & $5 \$ 7.0$ & um* & Sdo & 726.6 & $u m^{2}$ & Sde & $\cdots \cdots$ & $u m^{2}$ & Sde & 85.41 & $u m^{2}$ \\
\hline Sha & 1090 & um* & Sho & 440.4 & $u m^{2}$ & She & 693.1 & $\mathrm{um}^{2}$ & She & 78.51 & $u m^{*}$ \\
\hline Sodv & 5.042 & $\mu m^{\prime}$ & Sdo & 6.006 & un' & Sdo & $\cdots \cdots$ & um? & Sobv & 1.999 & $\mu m$ \\
\hline Shv & 2.957 & um? & Shr & 1.975 & um, & Shr & 13,44 & um? & Shr & 2.100 & vm, \\
\hline \multicolumn{6}{|c|}{ Standard used $=0.86 \mu \mathrm{m}$} & \multicolumn{6}{|c|}{ Standard used $=6.0 \mu \mathrm{m}$} \\
\hline
\end{tabular}

From Table I, using the main roughness parameters, we obtain Table II with a high correlation coefficient, thus authenticating the replica procedure used in this project.

Table II - Results coefficient of correlation

\begin{tabular}{|c|c|c|c|c|}
\hline \multirow[b]{2}{*}{ Parameters } & \multicolumn{4}{|c|}{ Comparative evaluation of standard versus replica } \\
\hline & $\begin{array}{c}\text { Original standard } \\
\text { roughness }=0,86 \mu \mathrm{m}\end{array}$ & $\begin{array}{c}\text { Replica } \\
\text { Roughness }\end{array}$ & $\begin{array}{l}\text { Original standard } \\
\text { roughness }=6,0 \mu \mathrm{m}\end{array}$ & $\begin{array}{c}\text { Replica } \\
\text { Roughness }\end{array}$ \\
\hline $\mathrm{Sq}$ & 0,8846 & 0,8856 & 6,883 & 6,896 \\
\hline Ssk & 0,1327 & 0,13 & 0,1021 & 0,07254 \\
\hline Sku & 1,558 & 1,56 & 1,782 & 1,813 \\
\hline $\mathrm{Sp}$ & 1,571 & 1,528 & 13,29 & 12,66 \\
\hline Sv & 1,437 & 1,45 & 11,67 & 12,49 \\
\hline Sz & 3,009 & 2,979 & 24,96 & 25,15 \\
\hline Sa & 0,79 & 0,7906 & 6,004 & 5,961 \\
\hline Coefficient of correlation & \multicolumn{2}{|c|}{0,999811602} & \multicolumn{2}{|c|}{0,998750436} \\
\hline
\end{tabular}




\subsection{Replica Analysis}

The equipment to perform the replica analysis of the surface topography, using international 3D roughness parameters, is shown in Figure 7.

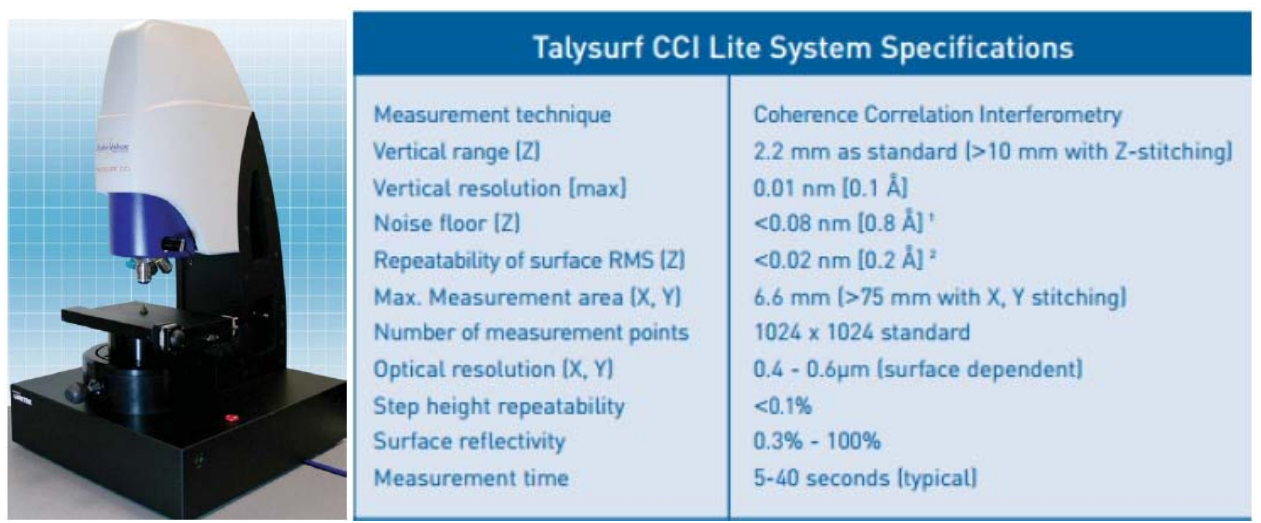

Figure 7. Image of the rugosimeter 3D - Talysurf CCI [3]

\subsection{Evaluation: Roughness test retention in a Temper Mill}

Roughness retention of a WRC $(\phi 425 \mathrm{~mm})$ has been determined at the Temper Cold Mill [12]. Figure 8, shows the application of the replica during the sampling on the rolls and on the sheet.

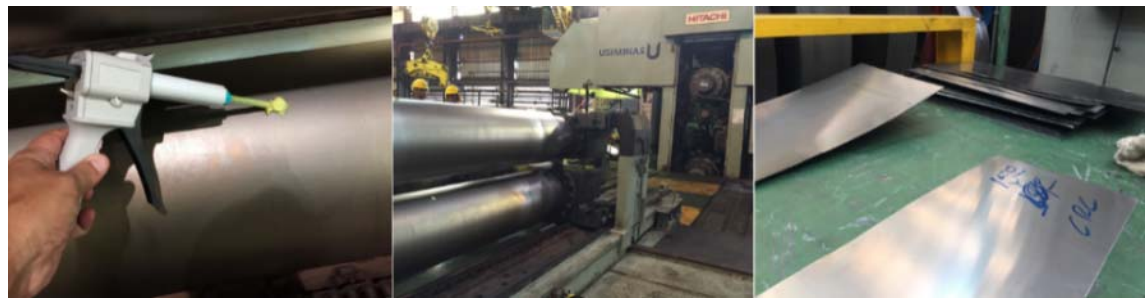

Figure 8: Application of replica on WRC/WRU and sheet at the Temper Mill [12]

In these trials, evaluation has been performed over several work roll campaigns and on the sheet metal, simultaneously. Replicas were applied on work rolls and onto the sheet, in three campaign steps, namely: beginning $(20 \mathrm{~km})$, middle (50 and $250 \mathrm{~km})$ and final (100 and $500 \mathrm{~km})$, respectively for WRC and WRU. These steps/positions were strategically defined in order to verify the wear out /evolution of roughness, both for the rolls and sheet. In Figure 9, illustrates the sampling schedule.

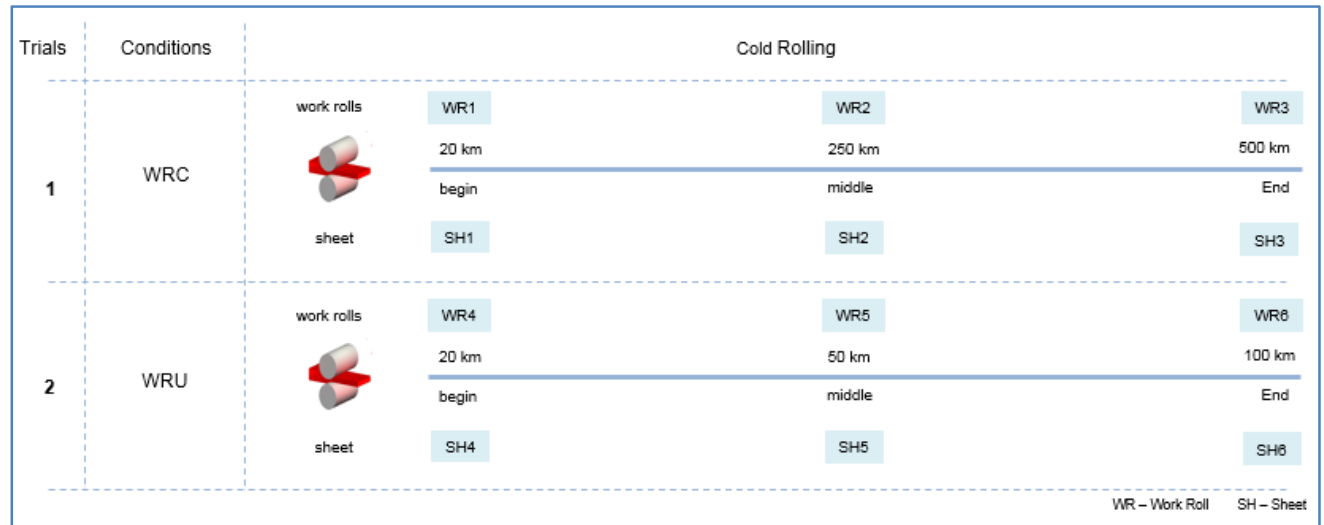

Figure 9: Application of replica on WRC and on the sheet at the Temper Mill 
About 30 coils were followed in these tests. The steel sheets were $1200 \mathrm{~mm}$ wide and $1.20 \mathrm{~mm}$ thick, and have been unidirectionally ( one way only) rolled up in one pass. Rolling was performed in the wet condition using a solution of about $2 \%$ soluble oil, with a reduction of $\cong 1 \%$.

\section{RESULTS AND DISCUSSION}

\subsection{Roughness Retention Tests (on the rolls)}

Tests have been carried out in order to evaluate the roughness retention of the rolls and sheet surfaces. Figure 10 shows the variation of Sa values for the WRC system.

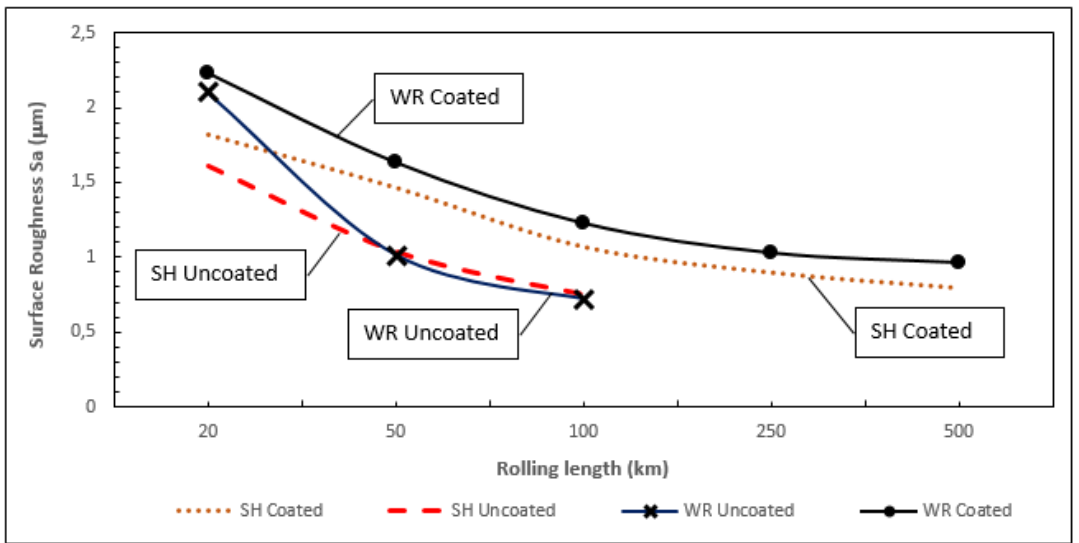

Figure 10: variation of Sa roughness with WRC surfaces with rolling length compared to WRU, solid lines from [10], dotted lines (present research for rolls), traced lines (present research for sheet (SH), see Fig. 6). Ra values (2D) are taken as being similar to Sa values (3D).

These results show that the roughness retention curves both from [10] and those from the present research show similar trend. Clearly, the WRC showed about five times higher performance than WRU, confirming the information given in [3].

\subsection{Evolution of the Surface Topology (on the steel sheet)}

Figure 10 also shows the evolution of the steel sheet roughness for the same conditions, which is the novel aspect of the present research. Furthermore, the 3Dsurface topology of the WR before and after applying HPC may be observed in figure 11. More details on 3D surface analysis may be obtained from [6] and [7]. 

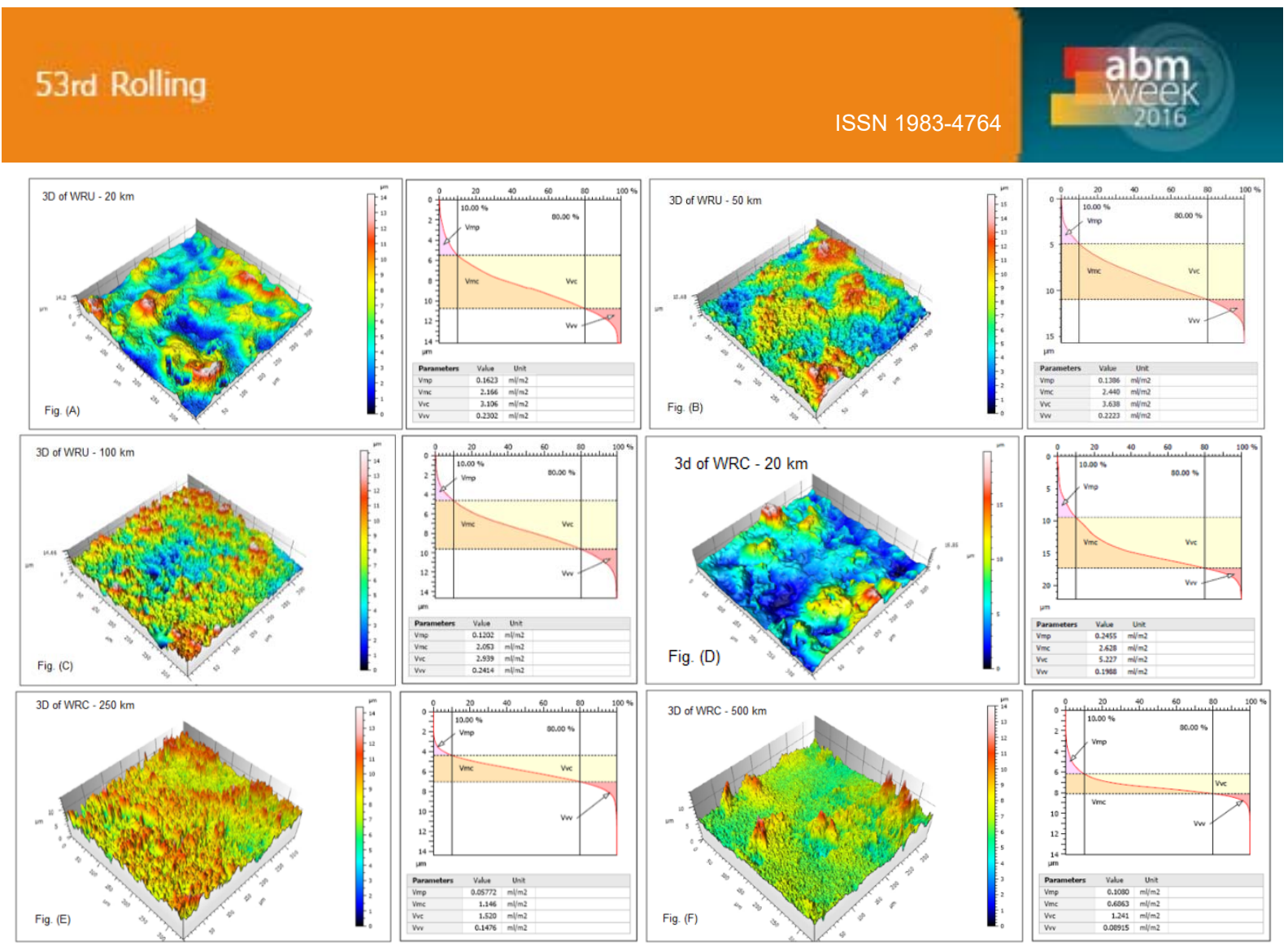

Figure 11: 3D roughness topology of the surface WRC/WRU and Abbot-Firestone curves

The present results of this preliminary research show, despite not allowing a clear resolution related to the wear mechanisms that were predominant; it was possible to compare both WRU and WRC chromed roll surfaces. Taking into account that the tribological system that is being analysed (for pure slip and boundary lubrication conditions), the parameters that present the greatest influence can be summarized in Table III:

Table III - Results of the surface topology (Figure 11)

\begin{tabular}{c|ccccc|ccccc}
\hline Parameter & \multicolumn{4}{c|}{ WRU (ml/m $\left.{ }^{2}\right)$} & \multicolumn{3}{c}{ WRC (ml/m $\left.{ }^{2}\right)$} \\
\hline \hline- & $20 \mathrm{~km}$ & $50 \mathrm{~km}$ & $100 \mathrm{~km}$ & Std. Dev. & Variation & $20 \mathrm{~km}$ & $250 \mathrm{~km}$ & $500 \mathrm{~km}$ & Std. Dev. & Variation \\
\hline Vmp & 0,1623 & 0,1386 & 0,1202 & 0,021 & $-0,04$ & 0,2455 & 0,057 & 0,108 & 0,098 & $-0,14$ \\
Vmc & 2,053 & 2,166 & 2,44 & 0,199 & 0,39 & 2,628 & 1,146 & 0,6863 & 1,015 & $-1,94$ \\
Vvc & 2,939 & 3,106 & 3,636 & 0,364 & 0,70 & 5,227 & 1,52 & 1,42 & 2,170 & $-3,81$ \\
Vvv & 0,2414 & 0,2302 & 0,2223 & 0,010 & $-0,02$ & 0,1988 & 0,1476 & 0,089 & 0,055 & $-0,11$ \\
\hline
\end{tabular}

From Table III, the WRC surface parameters present a greater volume of "peaks", above the material "core" and a smaller volume of "valleys" under the same material "core", when compared to the WRU, as shown by the images of Figure 11. Evaluating the main parameters separately we have:

a) Vmp: smaller wear of the WRC (at $500 \mathrm{~km}=0.108 \mathrm{ml} / \mathrm{m}^{2}$ ) in relation to the WRU (at $100 \mathrm{~km}=0.1202 \mathrm{ml} / \mathrm{m} 2$ ), probably due to the smaller contact area and, hence, smaller gouging/squeezing of the peaks during the rolling tests. It confirms the five fold increase in the roll campaign of the WRU as compared to the WRC, as shown by Figures 6[10] and Figure 10[3].

b) $\mathrm{Vmc}$ : reduction in the volume of the valleys in the WRC (at $500 \mathrm{~km}$ ), indicating that the Cr-layer contributes to the area sustaining the rolling load and, after a certain "milage", the effect is over. This might be related to the loss/ wear out of the Cr layer during the campaign. For the WRU, the volume of "valleys" after $100 \mathrm{~km}$ was nearly constant, as shown by Figure 5[3]. 
c) Vvv: For both WRC and WRU there was a reduction in the void volume. This may be related to the decrease in the amount of lubricant retention. However, the WRC presented a five -fold improvement when compared to the WRU, therefore confirming the Cr-layer in increasing this parameter, as shown in Figure 5 [3].

\section{CONCLUSION}

Based upon the present preliminary research work the following can be concluded:

1) The surface replica technique/methodology is reliable.

2) There is a Sa significant drop in the Sa values for the in the rolls and for the sheet when comparing WRU in relation to the WRC. Therefore, the WRU rolls showed lower roughness retention as compared to the WRC.

3) Explanations could be given through the Vmp, Vmc and Vvv parameters (not excluding eventual other 3D surface parameters). It is important to point out the methodology for monitoring simultaneously the evolution of roughness/surface texture of both work rolls and sheet roughness.

4) There is clearly an increase in roll campaign - of about five times, although technical and environmental care should be taken during the application of the hard chrome layer.

\section{Acknowledgments}

The authors gratefully thank the specialists from Usiminas-Cubatão and General Motors for the technical support given to this work.

\section{REFERENCES}

1 Simão, J., Aspinwall, D. K., F. El-Menshawy and K. Meadows, "Surface alloying using PM composite electrode materials when electrical discharge texturing hardened AISI D2", Journal of Materials Processing Technology , v. 127, p. 211-216, 2002.

2 Surface Finishing Technology; Dura Chrome Hard Chromium Plating. By Eric Svenson Plating Resources, Inc. Cocoa, Florida, USA 1980, 2006 - Table of Contents. File link: http://www.plating.com/Book.pdf

3 NUNES, Eduardo, et al. "Inter-Relationship among Skin Pass Reduction, 3D and 2D Roughness Parameters and the Stampability/Paintability of Cold Rolled Steel Sheets for the Automotive Industry: A Preliminary Analysis" [doi:10.4028/www.scientific.net/MSF.783-786.1039]. Materials Science Forum [online], v. 783-786, p. 1039-1045, 2014.

4 Giovanni B.; Giovanardi R.; Lusvarghi, L.; Manfredini, T.; "Corrosion Resistance of HVOF-sprayed Coatings for Hard Chrome Replacement”; Corrosion Science, v.48, Issue 11, p. 3375-3397, 2006.

5 De Mello, J. D. B.; Gonçalves Jr, J. L.; Costa, H. L. "Influence of surface texturing and hard chromium coating on the wear of steels used in cold rolling mill rolls". Wear, v. 302, n. 1-2, p. 1295-1309, 2013, ISSN 0043-1648.

6 Stout, K.J., et al. "The Development 01 Methods for the Characterization of Roughness in three dimensions", report EUA 15178 EN. EC Brussels, 1993, ISBN O704413132.

7 Stout, K.J., Sullivan, P.J., "The use of 3d Topographic Analysis to determine the microgeometric transfer Characteristics of textured Sheet Surfaces through Rolling", Annals of the CIRP, v.41, p.621-624, 1991

8 PAWELSKI, O.; RASP, W.; ZWLCK, W.; NETTELBECK, H.-J.; STEINHOFF, K. "The influence of different work roll texturing systems on the development of surface structure 
in the temper rolling process of steel sheet used in the automotive industry". Journal of Materials Processing Technology, v. 45, p. 215-222, 1994.

9 OLIVEIRA, A. F. Private communication on Jun 2013. Usiminas Cubatão Brazil.

10 Simão, J.; Aspinwall, D. K., "Hard chromium plating of EDT mill work rolls". Journal of Materials Processing Technology, v. 92-93, p. 281-287, 1999, ISSN 0924-0136.

11 LEITE, M.V., SANTOS, M. M., MELLO, J. D. B., LIMA, A. G., RAMOS, G. P., MACHADO, J. R., SANTOS, N. L., ROSARIO, C. S., OLIVEIRA, A. F., RAMPINELLI, M. E. G., ROCHA, S. S., FERREIRA, R. L. O., LESSA, R. A. G. "Mecanismos de desgaste de cilindros de trabalho dos laminadores tandem de tiras a frio do Brasil". In: 48 Seminário de Laminação, Processos e Produtos Laminados e Revestidos, 2011, Santos. Semin. ABM, 2011; Seminário de laminação processos e produtos laminados e revestidos, 48; Seminário de Laminação, 48. São Paulo: ABM, 2011. p. 728-738.

12 OLIVEIRA, A. F. "Caracterização de um aço IF após relaminação no laminador de encruamento". 2009. Dissertação (Mestrado em Engenharia Metalúrgica e de Materiais) - Escola Politécnica, Universidade de São Paulo, São Paulo, 2009.

13 Available in: http://www.teses.usp.br/teses/disponiveis/3/3133/tde-11082010-161554/ 